\title{
MIGRACIÓN, REMESAS E INDICADORES ECONÓMICOS EN LA COMUNIDAD ANDINA
}

\author{
Fernando Neira Orjuela*
}

\begin{abstract}
RESUMEN: Las remesas se han constituido en un elemento dinamizador de las economías de América Latina en general y de la Comunidad Andina en particular. Una de las principales manifestaciones de la importancia que tienen las remesas es el peso en los indicadores macroeconómicos. A este respecto, el presente artículo no sólo hace una caracterización de los flujos migratorios internacionales de los países andinos, sino que aborda de manera especial la forma como se han visto afectados lo indicadores macroeconómicos de la región por efecto de los recursos de las remesas.
\end{abstract}

PalABRAs ClAVE: Comunidad Andina, Migración, Remesas, Latinoamérica.

ABSTRACT: Remittances have become an element of dynamic economies in Latin America in general and the Andina Community in particular. One of the main manifestations of the importance of remittances is the weight in macroeconomic indicators. To this extent, this article not only a characterization of international migration flows in the Andina countries, but addresses in particular the way it has affected the macroeconomic indicators in the region by the resources of remittances.

KEY WORDS: Andina Community, Migration, Remittances, Latin America.

\section{INTRODUCCIÓN}

En la actualidad el envío de remesas es una fuente importante de capital en muchos países, pero el dinero que envían los latinoamericanos que viven y trabajan en estados europeos, y principalmente Estados Unidos, constituyen la mayor fuente de capital extranjero que llega a la región en

\footnotetext{
* Centro de Investigaciones sobre América Latina y el Caribe-UNAM (ferneira3@yahoo.com.mx).
} 
general y a la Comunidad Andina en particular. Un aspecto importante de los países que conforman la Comunidad Andina (Perú, Ecuador, Colombia, Bolivia y Venezuela) además de la intensiva migración entre estos países, es la fuerte presencia migratoria internacional que se manifiesta en una significativa presencia de migrantes andinos que viven en Estados Unidos, Canadá y, en especial, Europa. El presente artículo, tiene como objetivo principal caracterizar la dinámica migratoria y los envíos de remesas de los países de la Comunidad Andina en este siglo, en el marco de lo que ha sido la tendencia en América Latina. Para ello, el estudio se encuentra dividido de la siguiente manera: en primer lugar, se hace un análisis de la migración a Estados Unidos y Canadá; una segunda parte describe lo relacionado con los flujos a Europa, especialmente España y Asia; en tercer lugar, se da cuenta de los montos y características de las remesas y, por último, se describen los usos socioeconómicos de las mismas.

\section{LOS FLUJOS MIGRATORIOS ANDINOS: A ESTADOS UnidOS Y CANADÁ}

Pablo Serrano señala que hay más de 17 millones de latinoamericanos y caribeños fuera de sus países, 15 millones, o sea $88 \%$, se dirigió a Estados Unidos, con una contribución reconocida pero no suficientemente valorada en términos del desarrollo productivo de este país. Según este autor, los datos del Censo de Población del año 2000, los "hispanos" radicados en Estados Unidos ascendían a 35.3 millones, es decir 13\% de la población total, rebasando por primera vez a los afroamericanos como minoría. Esta cifra, según la misma fuente, no incluye a los indocumentados que, claro, no fueron censados y que, cuatro años atrás, mediante cálculos indirectos, se habían estimado en 5 millones, concentrados en California y Texas. ${ }^{1}$ De cada 100 emigrantes que hay en el mundo, más de 13 provienen de la región latinoamericana y caribeña, sin contar los indocumenta-

${ }^{1}$ Pablo Serrano, "Desarrollo y migración. Flujos migratorios y remesas en América Latina y el Caribe. La experiencia de la CEPAL", Revista Redes, núm. 8, febrero, 2002. 
dos y los trabajadores temporales que practican tipos de migración circular, con lo cual este porcentaje sufriría un aumento sustancial.

En el caso de los flujos migratorios andinos que se dirigen a Norteamérica, éstos tienen como una de las características principales la importante emigración de colombianos respecto de las otras nacionalidades. En este sentido, es de destacar que su número en Estados Unidos era en 1980 de 140 mil. Para 1990 ya se había duplicado su presencia con 286124, situación que vuelve a ocurrir diez años después, donde su población alcanzó un total de 470648 inmigrantes. $^{2}$

En relación con los otros países de la Comunidad Andina se puede señalar que si bien tienen un volumen importante en Estados Unidos, sus cifras son menores que los colombianos. Sin embargo, los flujos migratorios también se duplicaron, así que los ecuatorianos pasaron de casi 90 mil en los años ochenta, a cerca de 145 mil en los noventa y, para el 2000, alcanzaban los 260 mil. De los venezolanos es de destacar su incremento migratorio desde mediados de los noventa, que de contar con 35 214, prácticamente triplica su población al pasar a 91 mil. Asimismo, los peruanos experimentaron un significativo crecimiento y su número virtualmente se cuatriplicó (de 56 mil personas en los setenta a 233 mil para comienzos del tercer milenio). Los bolivianos, por su parte, han incrementado casi siete veces su población inmigrante al pasar de 6 mil en los setenta a 42 mil hacia el año 2000. ${ }^{3}$ Estados Unidos se constituye por lo tanto como la zona hacia donde se dirige mayoritariamente la población latinoamericana $\mathrm{y}$, en especial, de los países andinos como Colombia, Ecuador y Perú.

Estos migrantes andinos están en edades económicamente activas, es una población mayoritariamente masculina pero con un importante incremento de la participación laboral femenina. Se deben destacar tam-

2 Fernando Neira, "Caracterización sociodemográfica de la migración internacional de los países del Pacto Andino", en América Latina. Las caras de la diversidad, México, CCydel-unAm, 2006 (Serie Coloquios, 3), pp. 181-206.

3 Ibid. 
bién los altos niveles educativos, situación que tiende a ser más notoria con los flujos recientes. ${ }^{4}$ Finalmente, debe considerarse que los migrantes se insertan preferentemente en el sector terciario, con el predominio de actividades asalariadas.

En el caso de la migración latinoamericana a Canadá, no es tan significativa como la orientada hacia Estados Unidos, sin embargo, desde las últimas décadas se ha venido incrementado de forma importante. Goldring considera que Canadá es un destino reciente, pues es hacia mediados de los años sesenta que se tienen las primeras referencias de grupos caribeños, en donde arribaron más de mil mujeres jamaiquinas en el esquema de trabajadoras domésticas, después llegaron enfermeras. Años más tarde fueron trabajadores para el programa agrícola temporal, al que luego se le incorporaron trabajadores de Trinidad y Tobago y luego mexicanos. ${ }^{5}$ Hacia los setenta llegó otra oleada de latinos que arribaron como refugiados.

En Canadá los flujos migratorios fueron creciendo en la década de los ochenta, encontrándose una importante participación de inmigrantes de los países andinos, sobresaliendo Ecuador (5 745) y Colombia (5 170). Ya para los noventa destaca Perú (11 480), seguido de Ecuador (9 635) y Colombia (9 465), lo que muestra un incremento de inmigrantes andinos. Para comienzos del siglo XXI, sigue siendo en su orden Perú, después Colombia y Ecuador, los países que mantienen el mayor flujo de inmigrantes en Canadá. ${ }^{6}$ Esta migración si bien sobresale por ser un fenómeno reciente, tiene un importante crecimiento de la presencia de latinos en general y de los inmigrantes de la Comunidad Andina en particular.

En 2001 en Canadá había aproximadamente 212000 personas de origen hispano. Posteriormente, señala Schugurensky y Ginieniewicz,

\section{${ }^{4}$ Ibid.}

${ }^{5}$ Luin L. Goldring, "Re-thinking Remittances: Social and Political Dimensions of Individual and Collective Remittances", CERLAC Working Paper Series, York University, 2003.

${ }^{6}$ Fernando Neira, "La migración internacional de los países de la Comunidad Andina", Retos de la migración latinoamericana, México, CCyDEL-UNAM/IPGH, 2007, pp. 139-154. 
respondiendo a una solicitud del Congreso Hispano Canadiense, Estadísticas Canadá volvió a analizar los datos del censo utilizando una nueva definición de "hispano" que incluye tres criterios: a) origen étnico vinculado a un país de habla hispana; b) español como primera lengua; y c) nacimiento (propio o de sus padres) en país hispanoparlante. Cualquier persona que mencionó al menos una de estas tres características fue considerada de origen hispano. Según esta misma fuente a partir de esta nueva categorización, Estadísticas Canadá realizó un nuevo cálculo, de acuerdo al cual estimó que la cifra de hispanos residentes en Canadá era de 520260 personas. Es pertinente notar que esta definición de "hispano" incluye a los inmigrantes españoles y excluye a los brasileños. Para estos autores la categoría "latinoamericano", a la inversa, incluye a los inmigrantes de origen brasileño y excluye a los españoles. Si bien las categorías "comunidad hispana" y "comunidad latinoamericana" no son conceptualmente equivalentes, demográficamente se superponen bastante: según el censo de 2001 existe un número relativamente similar de inmigrantes de origen español y de origen brasileño viviendo en Canadá. De todos modos, esta cifra oficial de 520260 excluye a personas que no se autoidentificaron como "hispanos" en el censo y a muchos que no completaron el censo por temor (particularmente aquellos que carecen de documentos migratorios) o por otras razones. ${ }^{7}$

\section{Migrantes ANDINOS EN EUROPA Y ASIA}

Uno de los rasgos interesantes de la reciente migración internacional de los países de la Comunidad Andina es la tendencia a concentrarse cada vez más en el viejo continente. El crecimiento de la emigración hacia Europa tiene como sus momentos más importantes entre los años 1996 y 2001 , intervalo en el cual se duplica y en ocasiones se triplican los flujos

${ }^{7}$ Daniel Schugurensky y Jorge Ginieniewicz, "La comunidad latinoamericana en Canadá: algunos desafíos pendientes”, Diálogos de Revista en Línea, núm. 3, Toronto, verano 2007. "Ojos al norte: los latinoamericanos en Canadá", Toronto, Canadá, 2007. 
migratorios. ${ }^{8}$ Dichos flujos migratorios andinos crecieron en forma importante en la mayor parte de los países sobre todo en España.

El colectivo de emigrantes latinoamericanos en España está alcanzando una gran relevancia en los últimos años, ya que según La Confederación Española de Cajas de Ahorros, entre el decenio 1992-2001 su número se multiplica por 3.8, pasando de los 74077 emigrantes en 1992 a los 283778 registrados en diciembre de 2001. Este alto ritmo de crecimiento se ha intensificado paulatinamente en los últimos años, hasta el punto de que en junio de 2002 se alcanzó una cifra oficial de 388125 emigrantes de esa región, lo que supuso en los seis primeros meses de ese año un incremento de $36 \%$ en relación con las cifras de cierre de $2001 .{ }^{9}$

A fines de los años noventa y comienzos del nuevo siglo, la presencia de inmigrantes latinoamericanos gira en torno a dos nacionalidades: ecuatorianos y colombianos. En el caso de los primeros, para el año 2003 su número llegaba a 174289 , mientras que para los segundos las cifras eran de 107459 inmigrantes. ${ }^{10}$

Italia es otro de los destinos principales de los latinoamericanos, de ahí el crecimiento de la emigración que se dio entre 1996 y 2001. Para Pipa y Verdera, antes de 1991 este fenómeno no era importante según la información sobre la población emigrante registrada en Italia. Por ello es que se observa un salto de la emigración de Perú a Italia entre 1991 y 1996 y una nueva elevación en 2001. ${ }^{11}$ Los emigrantes andinos también

${ }^{8}$ Fernando Neira, "Los migrantes colombianos en México: una caracterización sociodemográfica" a publicar en el libro Los extranjeros en México que editará el Centro de Estudios Migratorios del INM-SEGOB, México.

${ }^{9}$ Confederación Española de Cajas de Ahorros, Las remesas de inmigrantes entre España y Latinoamérica, estudio elaborado por CECA, Caja Murcia, Caja de Ahorros El Monte de Sevilla y SADAI, España, 2002.

${ }^{10}$ Raquel Martínez Bujan, "La reciente inmigración latinoamericana a España”, CEPAL, Serie población y desarrollo, núm. 40, 2003.

${ }^{11}$ María Elena Pipa y Francisco Verdera, Emigración y remesas en los países andinos. Tendencias recientes y propuestas, OIT-Oficina Regional para América Latina y el Caribe, OIT-Oficina Subregional para los Países Andinos, 2004. 
tienen un peso importante en el Reino Unido donde sobresale la presencia colombiana. Según Velasco, Alemania es donde las mujeres constituyen el mayor porcentaje de la población total migrante, pues para el año 2005, de los 92 mil 799 latinoamericanos que residían en Alemania, 63 mil 120 eran mujeres. ${ }^{12}$

Otro país que registra un incremento de la comunidad andina es Suiza, país europeo con la más alta tasa de población inmigrante. Según Stienen, el último censo nacional del año 2000, 20.5\% de sus siete millones y medio de habitantes no tenía la nacionalidad suiza, al sobresalir la presencia latinoamericana en general y la andina en particular. En el año 2000, la población latinoamericana registrada en Suiza fue de 2.1\% del total de la población extranjera del país (de 1.5 millones de personas). Ello significa que la diáspora latinoamericana registrada en Suiza se ha duplicado durante la década de los noventa, de 15300 a 31000 personas. ${ }^{13}$ Según esta misma fuente, los migrantes provenientes de Colombia, Perú, Bolivia y Ecuador llegaron mayoritariamente a Suiza a mediados de los años noventa. Sin embargo, el "puente" que ha posibilitado su migración y permanencia en el país se construyó a partir de los años ochenta. Para la autora, se observan dos tipos de migración desde dichos países andinos hacia Suiza durante las últimas dos décadas, y ambos están dirigidos a la permanencia irregular en el país.

El primero, a finales de los años ochenta, es predominantemente masculino; el segundo, a partir de mediados de los años noventa, es sobre todo femenino. Hasta 1997, los ciudadanos de los países andinos, a excepción de Perú, no necesitaban visa para Suiza. De manera que durante la década de los ochenta y hasta mediados de los noventa era más fácil entrar al país. En esta época, un buen número de ciudadanos bolivianos, ecuatorianos y peruanos (algunos con pasaporte boliviano), en su

${ }^{12}$ Hypatia Velasco Ramírez, Feminizada la migración latinoamericana a Alemania. En http:/www.cimacnoticias.com/site/06122101-Feminizada-la-migr.15987.0.html.

${ }^{13}$ Angela Stienen, "Globalización, nuevas dinámicas urbanas y estrategias e integración de migrantes andinos indocumentados en Suiza", Economía, Sociedad y Territorio, vol. IV, núm. 13, México, 2003, pp. 27-62. 
mayoría hombres, lograron establecer un nuevo nicho económico en Suiza: la música callejera. Este nicho les posibilitó durante varios años la permanencia como indocumentados en el país. ${ }^{14}$

Por otra parte debe señalarse que Portugal cuenta con un stock de 75 mil inmigrantes latinoamericanos y caribeños, más de dos tercios de los cuales son nacidos en Brasil y otro $29 \%$ en Venezuela. También es relevante el incremento de bolivianos y colombianos en Francia. En relación con Asia es importante la presencia de peruanos en Japón, que es la segunda comunidad en importancia después de los brasileños. ${ }^{15}$

En términos generales, destaca la creciente migración proveniente de los países de la Comunidad Andina, que supera la presencia de otras nacionalidades latinoamericanas en los diferentes países europeos y de Asia, sobre todo, por ejemplo, los flujos de colombianos y ecuatorianos en España, así como la de peruanos y bolivianos en Italia.

\section{LAS REMESAS ANDINAS Y SUS EFECTOS ECONÓMICOS}

El creciente fenómeno migratorio de los países latinoamericanos, y en particular de la Comunidad Andina hacia países desarrollados, se ha ido traduciendo en un flujo creciente de remesas de dinero de estos emigrantes a sus países de origen. Tales remesas han tenido como resultado un incremento drástico en la última década, principalmente en Estados Unidos y Europa.

Según el informe "Panorama social 2005 de la CEPAL" las remesas de emigrantes latinoamericanos y caribeños a sus países sumaron unos 45000 millones de dólares en 2004, duplicando el monto de una década atrás, además de presentar un constante crecimiento. Esos recursos enviados por trabajadores emigrantes a sus familias insuflan grandes bocanadas de aire a la economía regional y rescatan de la pobreza a más de 2.5 millones de personas. ${ }^{16}$

\footnotetext{
14 Ibid.

${ }^{15}$ Neira, "La inmigración internacional...

${ }^{16}$ Comisión Económica para América Latina y el Caribe (CEPAL), Panorama social de América Latina 2005, Santiago de Chile, 2006.
} 
Las remesas andinas han tenido un incremento drástico en la última década, como resultado del aumento de la migración hacia Estados Unidos y Europa. Un estudio realizado por el FOMIN indica que los países andinos en América Latina y el Caribe son los que manifiestan el mayor crecimiento porcentual de remesas entre los años 2002 y 2003 en la región. Durante el año 2006 el valor de las remesas recibidas por la Comunidad Andina crecieron en $22.5 \%$ respecto al año anterior, pasando de 7510 millones de dólares en el 2005 a 9200 millones de dólares en el 2006. ${ }^{17}$

Cuando se revisan los montos de las remesas que envían los migrantes andinos se puede observar que Colombia es la nación que más ha presentado un incremento constante de remesas con tasas de crecimiento anual superiores a $21 \%$ a partir de 1999, al pasar de un nivel de US\$ 788 millones en 1998 a US\$ 2374 millones en 2002, para alcanzar en la actualidad cerca de 4 mil millones de dólares. Colombia con 3897 es, después de México y Brasil, la nación que más capta recursos por concepto de remesas en la región latinoamericana. Ello no es de extrañar si se tiene en cuenta que entre 1996 y abril de 2003 salieron del país en forma permanente $1.6 \mathrm{mi}$ llones de colombianos, la mitad de los cuales emigró entre 1999 y 2000. Sólo en 1999 salieron del país 22773 jóvenes entre 14 y 24 años. ${ }^{18}$

\section{Cuadro 1}

Monto de remesas (millones de dólares)

\begin{tabular}{|lccccccc|}
\hline País & 2000 & 2001 & 2002 & 2003 & 2004 & 2005 & 2006 \\
\hline Bolivia & 92 & 109 & 92 & 138 & 178 & 303 & 569 \\
Colombia & 1578 & 2021 & 2454 & 3060 & 3170 & 3314 & 3890 \\
Ecuador & 1317 & 1415 & 1432 & 1627 & 1832 & 2454 & 2916 \\
Perú & 718 & 753 & 705 & 860 & 1133 & 1440 & 1825 \\
CAN & 3704 & 4298 & 4683 & 5685 & 6313 & 7510 & 9200 \\
\hline
\end{tabular}

Fuente: Comunidad Andina, Secretaría General, Proyecto Estadística, BID.

${ }^{17}$ Comunidad Andina, Estadísticas de remesas en los países de la Comunidad Andina (2000-2006), Lima, Comunidad Andina, Secretaría General, octubre, 2007.

${ }^{18}$ Neira, "Los inmigrantes colombianos en México... 
En relación con los flujos de remesas de los demás países andinos es de señalar que también han tenido un incremento durante toda la década anterior. Según los datos que proporciona la Comunidad Andina, por ejemplo en 2006 el monto de remesas enviado por los bolivianos desde el exterior fue de 569 millones de dólares, valor superior en 477 millones de dólares respecto al año 2000 en el que se registraron 92 millones de dólares, cabe mencionar que se observó un descenso de 17 millones en el año 2002 respecto al 2001. De esta forma las remesas crecieron a una tasa acumulada promedio anual de $30 \%$ en el periodo 2000-2006. En Ecuador, el monto de remesas provenientes del exterior en 2006 fue de 2916 millones de dólares, valor superior en 1599 millones de dólares respecto al año 2000 (1 317 millones de dólares). Las remesas de estos países crecieron a una tasa acumulada promedio anual de $12 \%$ en el periodo 2000-2006 (véase cuadro 1). Para el caso de Perú, en 2006 el monto de remesas provenientes del exterior es de 1825 millones de dólares, valor superior en 1107 millones de dólares respecto al año 2000 (718 millones de dólares). Por lo tanto se observa que las remesas crecieron a una tasa acumulada promedio anual de $14 \%$ en el periodo 2000 2006, lo cual demuestra lo significativo de dichos envíos. ${ }^{19}$

Estos montos de remesas tienen un impacto relevante en los países receptores, que se ven reflejados en algunos indicadores económicos como es el PIB, el porcentaje de las exportaciones, las transferencias corrientes y la inversión extranjera. Pizarro considera que en América Latina la participación de las remesas en el PIB mostró que en 1995 éstas representaron $0.7 \%$ del PIB regional y para el año 2002 este porcentaje aumentó a 1.4. ${ }^{20}$ La participación de las remesas en el valor de las exportaciones de bienes presentó un patrón similar al anterior. Según Lozano, en los países con una base productiva poco diversificada, el monto de las remesas supera en más de $50 \%$. Por lo que se refiere a los indicadores

${ }^{19}$ Comunidad Andina, op. cit.

${ }^{20}$ Jorge Martínez Pizarro, "Panorama regional de las remesas durante los años noventa y sus impactos macrosociales en América Latina", Migraciones Internacionales, vol. 2, núm. 2, julio-diciembre, 2003, pp. 40-76. 
per cápita, las remesas por habitante aumentaron de 24 a 46 dólares en el conjunto de la región, entre 1995 y 2002, mientras que el PIB por habitante disminuyó de 3.4 a 3.1 dólares entre los mismos años. ${ }^{21}$

En relación a su peso en el PIB nacional de los países andinos se observa que sobresale Ecuador, donde las remesas tienen un impacto significativo, pues se muestra la tendencia de crecimiento desde comienzos de los años noventa, al pasar de $0.5 \%$ al inicio de la década y alcanzar $7.1 \%$ en la actualidad. En Ecuador, con un PIB per cápita de 1.489 USD en 2002, las remesas per cápita ascendieron a USD 129 dólares; pero lo más significativo es que el PIB per cápita de $40 \%$ más pobre de la población fue de sólo USD 153. En otras palabras, el impacto de las remesas sobre la población de bajos ingresos es muy importante. ${ }^{22}$

Gráfico 1. Porcentaje de Remesas respecto al PIB

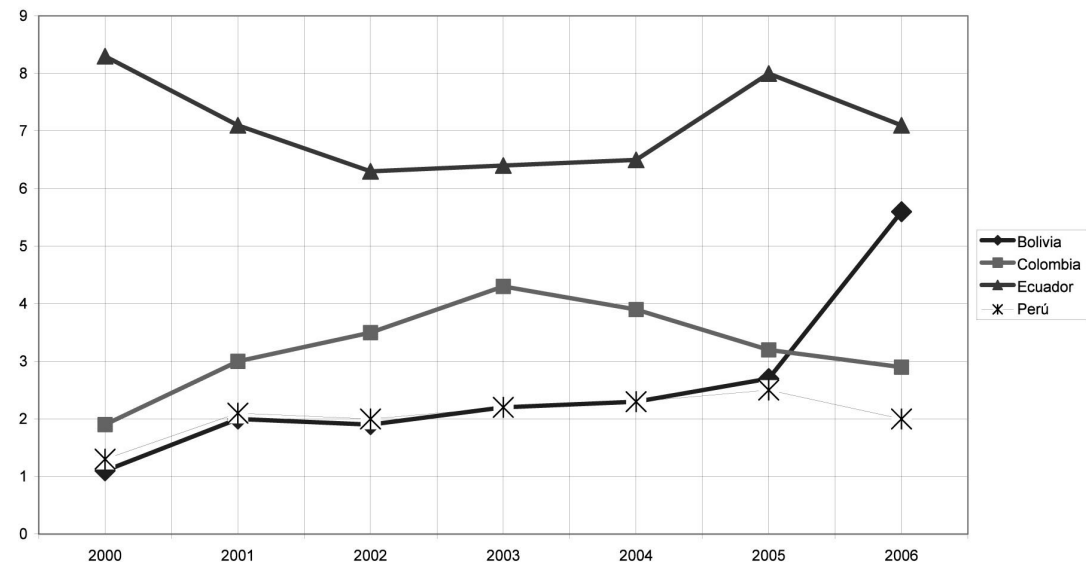

FUENTE: adaptado de COMUNIDAD ANDINA, Secretaría General, Proyecto Estadística, BID

${ }^{21}$ Fernando Lozano Ascencio, "Tendencias actuales de las remesas de migrantes en América Latina y el Caribe: una evaluación de su importancia económica y social”, estudio de la Secretaría permanente del SELA, elaborado por la Universidad Nacional Autónoma de México (UNAM), en Las remesas de inmigrantes y el Caribe: ¿Una alternativa de desarrollo en América Latina?, Caracas, Sistema Económico Latinoamericano (SELA), Corporación Andina de Fomento (CAF), julio, 2005.

${ }^{22}$ Andrés Solimano, "Remesas a los países andinos: costos e impacto económico", Conferencia, FOMIN-Quito, 12 de mayo, 2003. 
A partir de las estadísticas proporcionadas por la Comunidad Andina, en el caso de los demás países mencionados, debe señalarse que Colombia inicia su tendencia de incremento en el año 2000 con $1.9 \%$, siendo ascendente hasta el año 2003 donde se registra el valor de $3.9 \%$, posteriormente presenta una caída hasta registrar en el 2006 un valor de 2.9\% (véase gráfico 1). Para el caso de Bolivia y Perú, estos países presentan valores cercanos entre ellos a lo largo de casi todo el periodo, Perú inicia la tendencia con $1.3 \%$ y Bolivia con $1.1 \%$; hasta el año 2002 Bolivia es superado por Perú, a partir de 2003 sucede lo contrario, así las tendencias finalizan con $5.6 \%$ para Bolivia y $2.0 \%$ para Perú. ${ }^{23}$

Gráfico 2. Porcentaje de Remesas respecto a las exportaciones

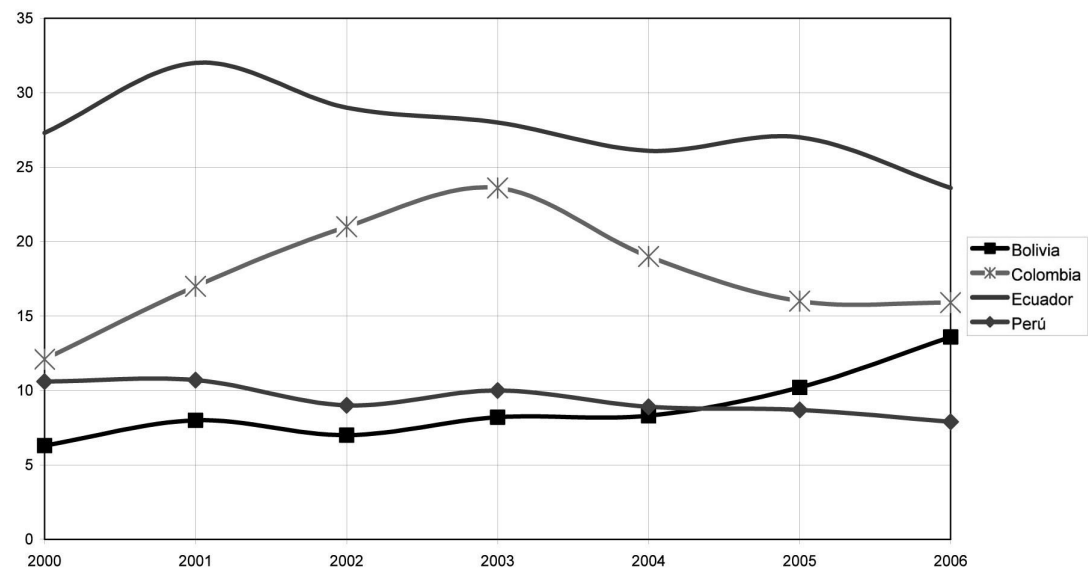

FUENTE: adaptado de COMUNIDAD ANDINA, Secretaría General, Proyecto Estadística, BID

Las remesas como porcentaje de las exportaciones muestran también registros interesantes. De nueva cuenta es Ecuador el país andino donde sobresale la representatividad económica de las remesas, ya que su crecimiento ha tenido aumento sostenido como lo demuestra el hecho de un crecimiento en el 2001 de $32 \%$ respecto al 2000 donde fue $27.3 \%$, luego se observa una tendencia descendente, llegando a registrar $23.6 \%$ en el

${ }^{23}$ Comunidad Andina, op. cit. 
2006 (véase gráfico 2). El porcentaje de las remesas respecto a las exportaciones en el caso de Colombia pasa por dos etapas, primero ascendente, de $12.1 \%$ en el año 2000 a 23.6\% en 2003, luego desciende hasta registrar $15.9 \%$ en $2006 .{ }^{24}$ Según esta misma fuente, en el caso de Perú y Bolivia, el porcentaje de las remesas respecto a la renta de las exportaciones se encuentran entre 6 a 13\% para el periodo 2000-2006.

Gráfico 3. Porcentaje de Remesas respecto a las transferencias corrientes

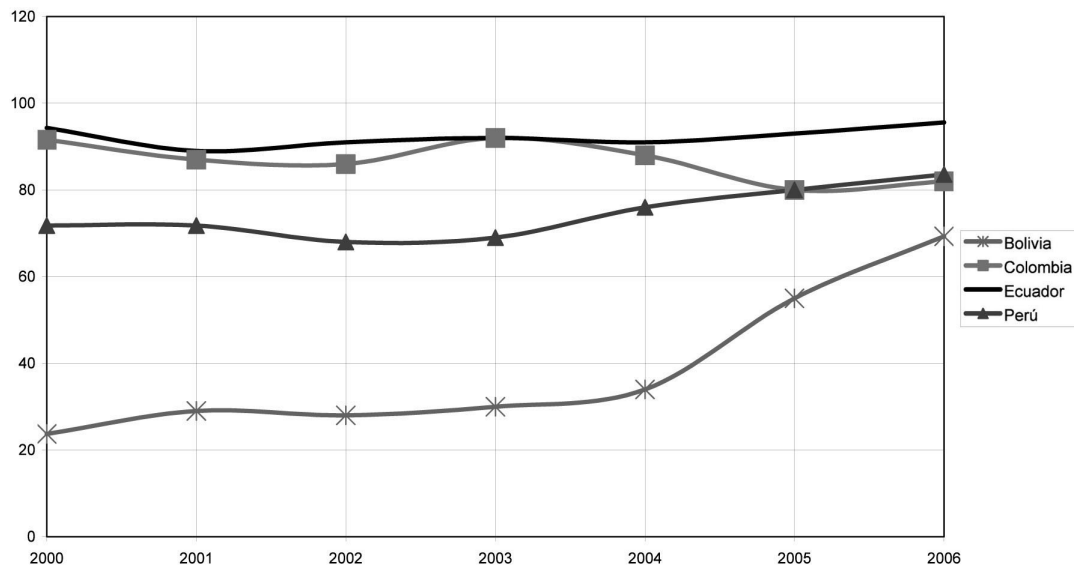

FUENTE: adaptado de COMUNIDAD ANDINA, Secretaría General, Proyecto Estadística, BID

Sobre las remesas y las transferencias corrientes se observa que durante el periodo (2000-2006), las estadísticas de la Comunidad Andina muestran que las remesas de los emigrantes representaron en conjunto $82.2 \%$ en promedio del valor total de las transferencias corrientes, calculándose para el año 2006 el valor de $85.3 \%$ (véase gráfico 3). Para el año 2006, los países que han presentado mayor porcentaje de remesas respecto al total de transferencias corrientes son Ecuador (95.6\%), Perú (83.6\%), Colombia (82.1\%), seguidos de Bolivia (69.3\%). ${ }^{25}$

\footnotetext{
${ }^{24}$ Ibid.

${ }^{25}$ Ibid.
} 
Gráfico 4. Porcentaje de Remesas respecto a inversión extranjera

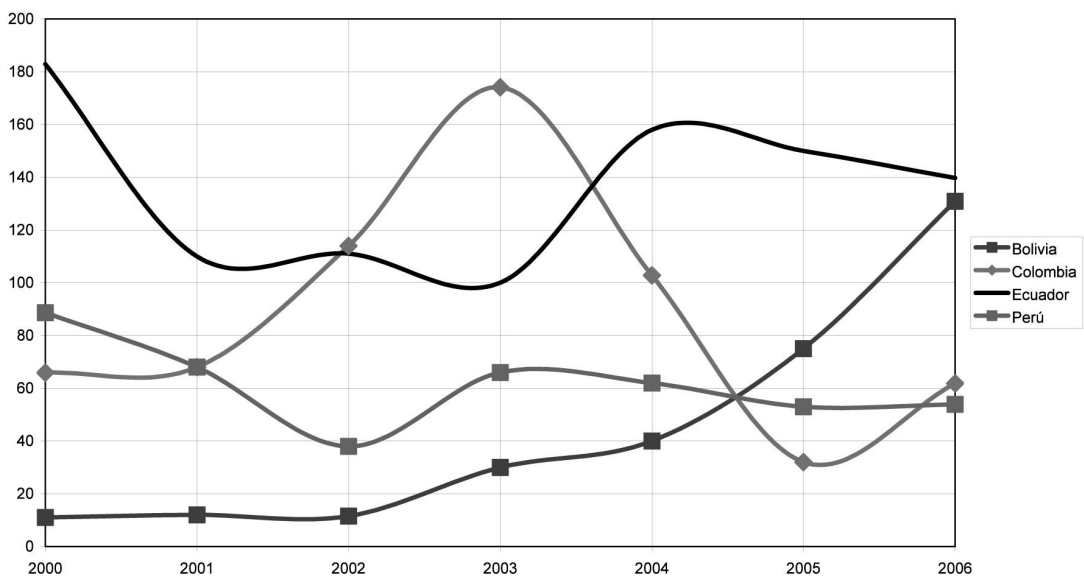

FUENTE: adaptado de COMUNIDAD ANDINA, Secretaría General, Proyecto Estadística, BID

Finalmente, al mirar la relación de las remesas andinas con la inversión extranjera se nota cómo las remesas de los emigrantes han representado en términos generales $79.6 \%$ en promedio del valor total de la inversión extranjera, calculándose para el año 2006 el valor de 75.4\%. Pese a la magnitud alcanzada por la inversión extranjera, para el caso ecuatoriano, el aporte de la emigración, a través del flujo de remesas, aparece con un monto cuantitativamente superior, durante el periodo 2000 (182.9\%) al 2006 (139.7\%) (véase gráfico 4). Las remesas para el caso colombiano superan los montos de inversión extranjera en los años 2002 (114.7\%), 2003 (174.1\%) y 2004 (102.8\%), observándose una caída en el 2006, debido principalmente al crecimiento de la inversión extranjera, pero menos acentuada que la caída de 2005. A partir de las estadísticas proporcionadas por la Comunidad Andina se observa cómo el monto de remesas que envían del exterior hacia Bolivia y Perú no superan los montos de inversión extranjera, sin embargo los porcentajes de representatividad son considerables; para el año 2006 en Bolivia el crecimiento de las remesas superó a la inversión extranjera, registrando 
$130.9 \%$ de participación. ${ }^{26}$ Lo anterior deja claro la importancia económica de las remesas para la región latinoamericana en general y para los países andinos en particular.

\section{CONCLUSIONES}

La Comunidad Andina ha logrado consolidarse en las últimas décadas como una organización que ha fortalecido sus procesos de integración local y regional en los ámbitos económico y político. Sin embargo, las crisis económicas por las que han atravesado estos países ha llevado a que en la última década se haya presentado una fuerte tendencia migratoria internacional, que se manifiesta en una significativa presencia de flujos migratorios, al sobresalir los inmigrantes que viven preferentemente en Estados Unidos, seguidos de los que viven en Europa. Respecto a la emigración andina a Canadá, ésta no es tan significativa como la orientada hacia Estados Unidos, sin embargo, es un destino reciente desde la década de los ochenta, al destacar la presencia de peruanos, colombianos y ecuatorianos.

De la emigración a Europa se debe enfatizar que de haber presentado una tendencia reducida hasta los noventa, para comienzos del actual siglo, al igual que lo ocurrido para Estados Unidos y Canadá, los flujos migratorios crecieron en forma importante. Debe señalarse la creciente presencia de migrantes andinos que superan otras nacionalidades latinoamericanas en los diferentes países europeos y de Asia, destacándose los flujos de colombianos y ecuatorianos en España, así como la de peruanos y bolivianos en Italia.

Sobre lo relacionado con las remesas, debe mencionarse que en América Latina y el Caribe los montos que enviaron los emigrantes a sus países fueron equivalentes a 70\% del monto total estimado de inversiones extranjeras en la región y superaron en 500\% la asistencia oficial al desarrollo. Con ello queda evidenciada la importancia económica de 
las remesas, no sólo por los montos que se han venido incrementando en los últimos años, sino por el hecho de su significación en indicadores como el PIB, el porcentaje de las exportaciones, las transferencias corrientes y la inversión extranjera.

El análisis de la relación entre los indicadores económicos y el flujo de remesas enviado hacia sus países de origen por la diáspora andina, deja claro que se ha modificado la dinámica de los flujos financieros regionales. El impacto de las remesas tiende a ser mayor en los países pequeños (como es el caso de Ecuador), con altos niveles de pobreza y con una estructura productiva menos diversificada.

Las remesas si bien implican beneficios no sólo en los indicadores económicos, su mayor importancia tiene que ver con el hecho de que ofrecen un apoyo económico real a los familiares de migrantes de zonas pobres, son también la posibilidad de generar riqueza en el hogar y en la comunidad, al igual que representan una obligación y un compromiso de atender las necesidades de la familia. En general, se entiende que las remesas pueden significar un alivio a la situación de pobreza, pero de carácter temporal, sin embargo ello debe ser mirado con cuidado, pues transformar los flujos de remesas en capital para el desarrollo requiere cambiar la naturaleza de estos fondos, de un fin compensatorio que tienen ahora, en inversiones. Esto implica que existan políticas claras para convencer a los remitentes y a los receptores de los fondos de que pueden obtener beneficios reales por invertir una parte del dinero para fines productivos y sociales. De no ser así, se corre el riesgo de perder una gran oportunidad de generar desarrollo local en los países de la región latinoamericana y, en especial, de los andinos.

Recibido: 15 de octubre, 2008. Aceptado: 15 de enero, 2009. 


\section{BIBLIOGRAFÍA}

COMUNIDAD ANDina, Estadísticas de remesas en los países de la Comunidad Andina (2000-2006), Lima, Comunidad Andina, Secretaría General, octubre, 2007.

Comisión EconómicA Para América Latina y el CARIBe (CEPAL), Panorama social de América Latina 2005, Santiago de Chile, 2006.

CONFEDERACiÓn EsPaÑola de CAJAs de Ahorros, Las remesas de emigrantes entre España y Latinoamérica, estudio elaborado por CECA/Caja Murcia/Caja de Ahorros/El Monte de Sevilla/SADAI, Madrid, 2002.

Goldring Luin L., "Re-thinking Remittances: Social and Political Dimensions of Individual and Collective Remittances", CERLAC Working Paper Series, York University, 2003.

Lozano Ascencio, Fernando, "Tendencias actuales de las remesas de migrantes en América Latina y el Caribe: una evaluación de su importancia económica y social, estudio de la Secretaría Permanente del SELA, elaborado por la Universidad Nacional Autónoma de México (UNAM)”, en Las remesas de migrantes y el Caribe: ¿Una alternativa de desarrollo? en América Latina, Caracas, Sistema Económico Latinoamericano (SELA)/Corporación Andina de Fomento (CAF), julio, 2005.

MARTÍNEZ BuJAN, RAQUEL, "La reciente inmigración latinoamericana a España”, CEPAL, Serie Población y Desarrollo, núm. 40.

Martínez Pizarro, Jorge, "Panorama regional de las remesas durante los años noventa y sus impactos macrosociales en América Latina", Migraciones Internacionales, vol. 2, núm. 2, julio-diciembre, 2003, pp. 40-76.

NeIRA, Fernando, "La migración internacional de los países de la Comunidad Andina", en Retos de la migración latinoamericana, México, CCyDEL-UNAM/IPGH, 2007, pp. 139-154.

, "Caracterización sociodemográfica de la migración internacional de los países del Pacto Andino", en América Latina: las 
caras de la diversidad, México, CCydel-UnAm, 2006 (Serie Coloquios, 3), pp. 181-206.

, "Los inmigrantes colombianos en México: una caracterización sociodemográfica", Los extranjeros en México [en prensa]. Pipa, María Elena y Francisco Verdera, Emigración y remesas en los países andinos. Tendencias recientes y propuestas OIT-Oficina Regional para América Latina y el Caribe, OIT-Oficina Sub Regional para los Países Andinos, 2004.

Schugurensky, Daniel y Jorge Ginieniewicz, "La comunidad latinoamericana en Canadá: algunos desafíos pendientes", Toronto, 2007. "Ojos al norte: los latinoamericanos en Canadá", Diálogos. Revista en Línea, núm. 3, Toronto, 2007.

SERrano, Pablo, "Desarrollo y migración. Flujos migratorios y remesas en América Latina y el Caribe: la experiencia de la CEPAL", Revista Redes, núm. 8, febrero, 2002.

SOlimAno, ANDrÉs, "Remesas a los países andinos: costos e impacto económico", Conferencia-FOMIN-QUITO, 12 de mayo, 2003.

STIENEN, ANGELA, "Globalización, nuevas dinámicas urbanas y estrategias de integración de migrantes andinos indocumentados en Suiza", Economía, Sociedad y Territorio, vol. IV, núm. 13, México, 2003, pp. 27-62.

Velasco Ramírez, HyPatia, Feminizada, la migración latinoamericana a Alemania. En http:/www.cimacnoticias.com/site/06122101-Feminizada-la-migr.15987.0.html. 